\title{
Water Quality Monitoring Sensors Optimum Location in a Metropolitan Supply Network
}

\author{
ALBERT TITUS CONSTANTIN*, GHEORGHE I. LAZAR, SERBAN-VLAD NICOARA \\ Politehnica University Timisoara, Faculty of Civil Engineering, Department of Hydrotechnics, George Enescu Str., 300022 , \\ Timisoara, Romania
}

The discrete numerical model developed by the help of TEVA-SPOT specialized software toolkit serves to a subsequent analysis that looks to estimate the water distribution system vulnerability in case of a contaminant agent release. The optimum location of the water quality sensors attached to a number of joints in the Timisoara (Romania) metropolitan water supply network can be reached in order to warn the company management and competent authorities and so to reduce the contamination effects upon the consumers.

Keywords: water network distribution, water quality monitoring, numerical modelling

EPANET [1] is a software largely engaged for modelling the hydraulic and quality phenomenon development in water distribution systems either at a given moment or along an extended simulation period of time. The simulation by a numerical model can evaluate the flow and the contaminant (agent) spread behaviour over chemical interaction. The water quality component of EPANET is restricted to transport surveillance, respectively to the outcome of a single chemical substance such as fluorine, which may be engaged in a tracing study, or as chlorine, engaged in a disinfectant decomposition study. There is a specific software extension - EPANET-MSX [2] - that allows modelling of a multiple system of chemical substances interactions, a capacity incorporated in a designated execution computer program with a library of function tools that the user can employ in order to develop personalized applications. Numerous water quality applications concerning the distribution systems can be performed by considering an approach of several specifications. The EPANET software with its EPANET-MSX extension are incorporated by the TEVA-SPOT computer program that also includes other modules performing analysis of system vulnerability at a contaminant release (Ensemble Vulnerability Assessment) corroborated with quality sensors optimum positioning (Sensor Placement Optimization Tool). The specialized packages of programs were developed at Sandia National Laboratories, U. S. Environmental Protection Agency [3,4].

The optimization and sensors placement problem have a solving approach which can be as default or user specified, both cases with a mathematical description. According to a Mixed Integer Programming formulation (MIP), the solutions consider the Sensor Placement Optimization Tool (SPOT) of standard type - expect-impact Sensor Placement (eSP) - that minimizes the expected impact of a contamination incidents assembly for a given sensor budget. Therefore, the most studied general sensor with placing formulation regarding Contaminant Warning Systems (CWS) is the impact minimization one. This became the SPOT standard formulation as it can be employed for defining effective sensors placement in large water distribution networks. An MIP formulation of an eSP type is represented by the mathematical construction given as follows:

(eSP)

subject to

where

and to

where

$$
\begin{aligned}
& \quad \min \sum_{a \in A} \alpha_{a} \sum_{i \in L_{a}} d_{a i} x_{a i} \\
& \sum_{i \in L_{a}} x_{a i}=1 \\
& x_{a i} \leq s_{i} \quad \forall a \in A, i \in L_{a} \\
& \quad x_{a i} \leq 1-s_{i} \quad \forall a \in A, i \in L_{a} \backslash\{q\}
\end{aligned}
$$

*email: albert.constantin@upt.ro 
Each contamination incident $\boldsymbol{a}$ from the group $\boldsymbol{A}$ comes according to its $\boldsymbol{\alpha}_{\boldsymbol{a}}$ weight, usually given as a probability. The formulation considers the integrated results of contamination simulation as referred to a group of locations $\boldsymbol{L}$, a location being attached to a network joint. There is a group of locations $\boldsymbol{L}_{\boldsymbol{a}}$ that may be contaminated due to the $\boldsymbol{a}$ incident. Thus, a sensor at a location $\boldsymbol{i} \in \boldsymbol{L}_{\boldsymbol{a}}$ can detect the first contamination incident that reaches that $\boldsymbol{i}$ location, each incident being so assisted by the first sensor that "see" it. A contamination impact $\boldsymbol{d}_{\boldsymbol{a} i}$ is defined for each $\boldsymbol{a} \boldsymbol{\epsilon}$ incident as it is assisted by an $\boldsymbol{i} \in \boldsymbol{L}_{\boldsymbol{a}}$ location. This impact measure assumes that once a contamination has witness sensors, then any other contamination effects are attenuated, considering a proper delay that takes into account the responding time of water user. The $\boldsymbol{s}_{\boldsymbol{i}}$ variable indicates which sensors are placed in the network, $\boldsymbol{c}_{\boldsymbol{i}}$ is the placement cost of a sensor in location $\boldsymbol{i}$, while $\boldsymbol{p}$ is the referenced budget. The $\boldsymbol{x}_{\boldsymbol{a} i}$ variable indicates if the $\boldsymbol{a}$ incident is sensor assisted in the $\boldsymbol{i}$ location. Technically, the user is not able to monitor all the contamination incidents by the help of the group of sensors. If one considers that a locations group $\boldsymbol{L}$ contains an inactive dummy location $\boldsymbol{q}$ which is to be found in all $\boldsymbol{L}_{\boldsymbol{a}}$ sub-groups, the impact for this location can be handled in two different ways: (1) as a contamination incident impact at the end of the entire pollutants transport simulation, without CWS on-line notice, or (2) as a zero-impact event. The first approach considers detection by this dummy location as a penalty, while the second one simply ignores this kind of detection (it should at least impose additional constraints with respect to the number of failed detections). The eSP formulation is a generalization of the sensor placement model described by Berry et.al. [5], reaching the conclusion that the theoretical problem is identical to the known $\boldsymbol{p}$-median one [6] as applied for a sensor placement cost $\boldsymbol{c}_{\boldsymbol{i}}=\mathbf{1}$. The $\boldsymbol{p}$-median problem of $\boldsymbol{p}$ given facilities to be considered on $\boldsymbol{m}$ potential sites looks to reduce to the minimum the summation of $\boldsymbol{d}_{\boldsymbol{a} i}$ distances to each of the $\boldsymbol{n}$ clients. As associating an expect-impact Sensor Placement formulation to the conventional p-median problem, one can notice the correspondence between: (a) sensors and facilities, (b) contamination incidents and clients, and (c) contamination impact and distances. While the eSP allows the placement of several sensors, the $\boldsymbol{p}$-median usually covers approaches of placing all its $\boldsymbol{p}$ facilities. Still, this difference is irrelevant in practice excepting the case when $\boldsymbol{p}$ comes close to the number of possible locations.

\section{Modelling of the metropolitan water supply network-EPANET2.0}

Timişoara is the municipality of Timiș County, Banat Province of Romania. Lying on the West of the country on the banks of Bega River towards of the Hungarian and Serbian borders, Timişoara (figure 1) is the third main town of Romania, with a population of about 306,585 and a functional urban area inhabitants number of about 508,037.

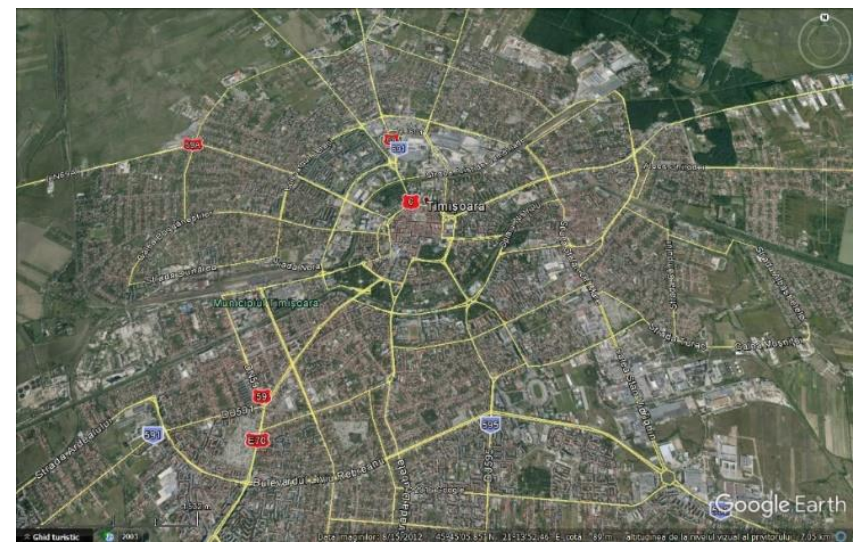

Fig. 1. General plan view of Timişoara Town, Romania

The water supply network spread was topographically measured and overlaid to the Timişoara street plan. The distribution system was meshed in a scaled scheme formed by pipe sections of various diameters and joints of specified topographic coordinates $(\mathrm{x}, \mathrm{y}, \mathrm{z})$. The water requirements on all joints are known [7,8] and so the entire supply network was numerically generated by the help of EPANET 2.0 software, considering an extended simulation time period of 48 hours. Further on, specific attuning and validation operations were performed upon the hydraulic model, regarding also the water quality. The generated and validated numerical model, symbolically presented by the paper, are going to be loaded with TEVA-SPOT computer program. Some relevant elements regarding the network development and running are visualized as follows: water flow development with time at the 5 main supplying pumps (fig. 2), water flow on pipe sections and joints pressure head developments at several specific moments along the 48 hours simulated period (fig. 3 ). 


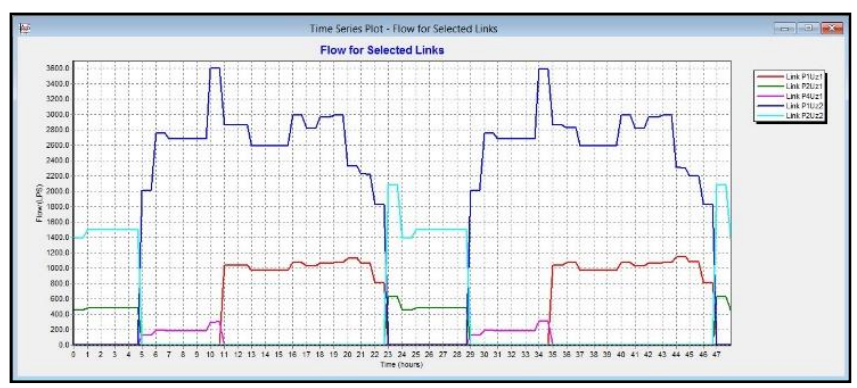

Fig. 2. Water discharge development over the considered 48 hours running of the 5 main pumps at the two drinking water supply plants
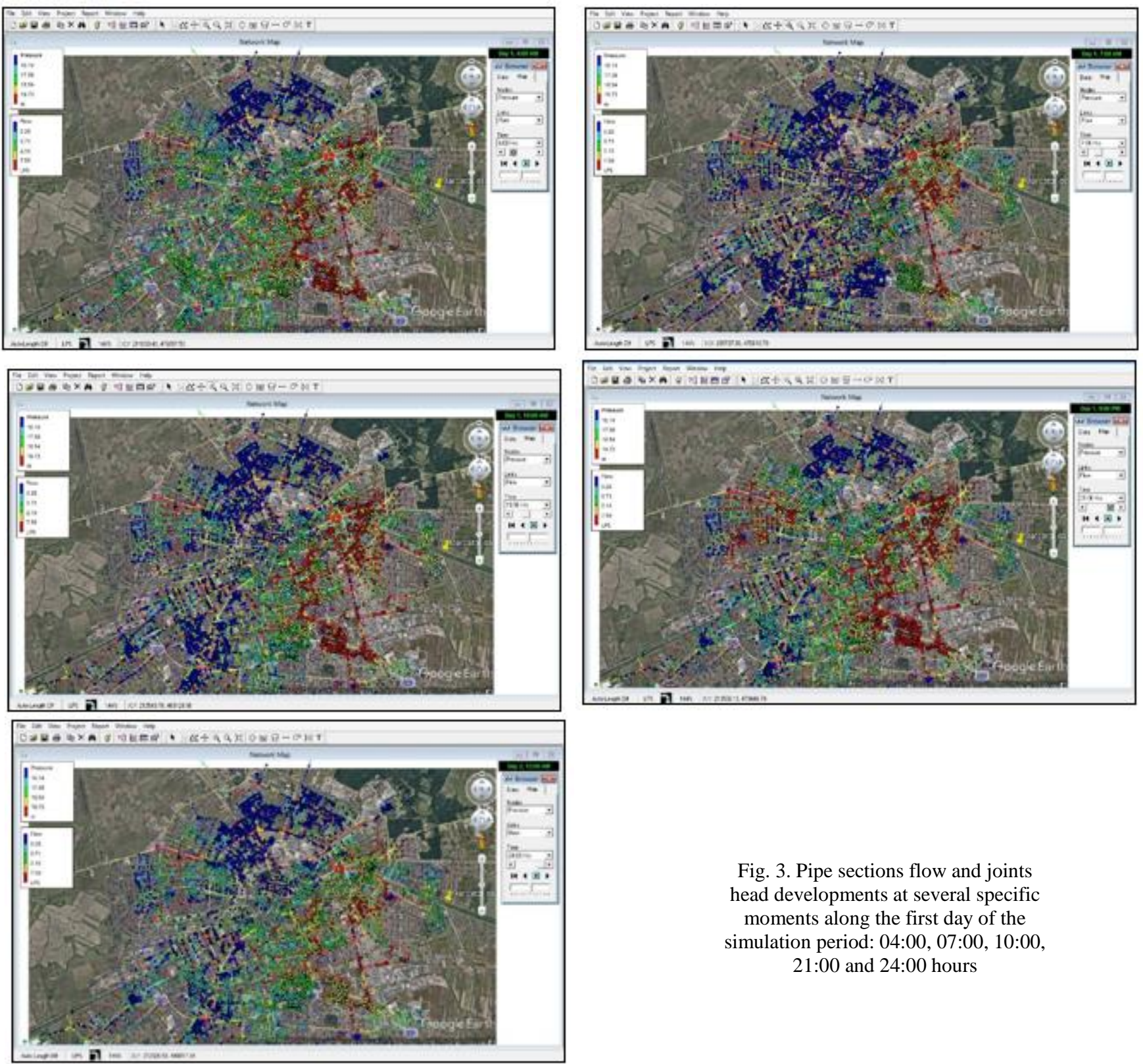

Fig. 3. Pipe sections flow and joints head developments at several specific moments along the first day of the simulation period: 04:00, 07:00, 10:00, 21:00 and 24:00 hours

\section{Loading the metropolitan water supply network model with TEVA-SPOT 2.3.2}

TEVA-SPOT allows the user to define various scenarios of contamination numerical simulation in drinking water distribution systems, studying the contaminant/contaminants spread and eventually the its consequences. Than results can be expressed in a variety of spreadsheets and graphs. The main goal of such a numerical simulation and following analysis is to establish the supplying network vulnerability to contaminants release and respectively to estimate the optimum locations for placing a set of water quality sensors that would help in reducing the pollution effects.

Additional info regarding assimilation of full EPANET-MSX type capacities can be gain by revising the software accompanying user manual [2]. Specific capacities assimilation determines several unnoticed alterations upon the 
EPANET model, such as adaptation of data storing structure which will set up the EPANET-MSX contaminants concentration data. The following steps need to be performed in order to run MSX capabilities with TEVA-SPOT:

- defining of a new ensemble;

- upload of the standard EPANET file of .INP extension modelling the distribution system;

- upload of the contaminants concentration data from the specific EPANET-MSX file;

- selection of the specific situation single / multiple contaminant under the Injection Definition;

- selection / stipulation of contaminant definition data - name, species, start and stop moment (the available species are given according to what is previously established by the EPANET-MSX file);

- stipulation of the Mass Injection Rate, the Concentration Zero Threshold and the Water Quality Tolerance for the multiple contaminants.

One would also need to look for the followings: definition of joints groups which allow us to specify contamination scenarios by a random process; definition of output files helping in the health impact analysis (to detail the joints where the population received a specific or an over-dose of contaminant) and the infrastructure impact analysis (total contaminated pipe length at a specific or an over-dose); definition of the consumer ingestion calendar from water tap along the day; definition of the cases number with most serious scenarios. The Health Impact Analysis (HIA) module allows the user to study a number of scenarios considering several dose levels under the given contaminant concentration data.

The routine procedures regarding the TEVA-SPOT program launching and employment for the considered study case follow the specifications presented by the specific user's manual $[3,4]$. Figure 4 shows the standard menu of TEVASPOT, starting from importing sequence of the EPANET pre-created inp file containing all input data modeling the Timişoara drinking water distribution system. Once the graphic representation shows up, the user would select the water tap icon in order to reach for several options offered by pull-down submenus. The Execution Control options window is to be accessed in the main menu in order to reach the edit and validation resources regarding the network characteristics, the scenarios, the health and infrastructure impact modules and the sensors placement facilities. As about the Quality option, the Chemical analysis type is settled.

The considered input parameters for the Ensemble module in TEVA-SPOT, as corresponding to Timişoara water distribution network, are mentioned by table no.1. We mention that TEVA-SPOT runs for an extended simulation period considering at least one contaminant agent.

The EPANET.MSX file containing the standard lines regarding the contaminant agents [2] was imported and the CLS class was selected for the first contaminant in Ensemble options menu. For each of the four distinct available executions under Execution Control sub-menu - Input Generation, Scenarios, Modules (HIA/TSOIA/IIA) and Sensor Placement (figure 4, upper-left) - there is available an Edit option, a box to be checked for running and an automatic validation in case of proper run. The Population number - 306,585 inhabitants - was specified after going for Edit option at Initialization Population in Input Generation (figure 4, down-left). The water usage per capita (gallons/day) is automatically estimated after clicking the Calc option. By confirming, the Initialisation Population becomes valid and its side box is to be checked by hand. The Execute option becomes valid and the model can be run. Once the execution is done without another user interfering, Terminate option becomes valid and the red cautioning dot turns as approving green meaning the running result is appropriate and the next stage can be approached.I
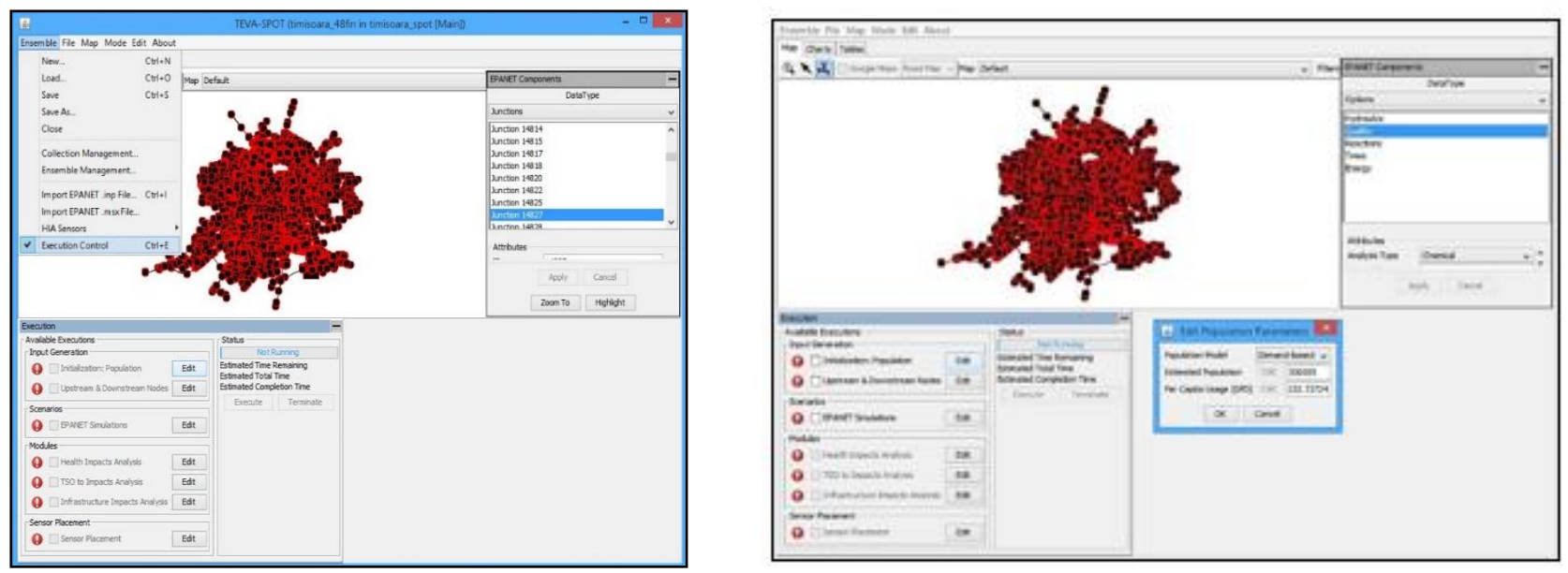

Fig. 4. Running resources of TEVA-SPOT: upper-left - network characteristics, scenarios, impact modules, sensors placement; down-right Chemical analysis with respect to the Quality option; down-left - the Edit option under Input Generation menu in order to specify population 
The figure 5 shows the specification regarding the 48 hours duration as data edit for Upstream \& Downstream Nodes under Input Generation execution. Once the edit is confirmed the attempted execution option becomes valid and, by running it, the red cautioning dot turns as approving green.

The figure 6 shows the accessing of Scenarios execution with its edit sub-windows. The first substance to be injected in the water distribution network is defined as of CLF (chemical as fluoride) species, with a mass injection rate of 50 $\mathrm{mg} / \mathrm{min}$ between the start time 0 and stop time 1 hour, an acceptable limit (concentration zero threshold) of $0.001 \mathrm{mg} / \mathrm{l}$, a calculated concentration tolerance of $1.0 \mathrm{E}-6 \mathrm{mg} / \mathrm{l}$. After confirming the considered data, the Agent \#1 is assigned to all the joints associated with the designated pipes (some defined as with diameter from $400 \mathrm{~mm}$ to $1600 \mathrm{~mm}$ in this specific case). The elements regarding Agent \#1 are then added to the defined Scenario Set.

Table 1

INPUT PARAMETERS FOR ENSEMBLE MODE IN TEVA-SPOT

\begin{tabular}{|c|c|c|}
\hline & INPUT parameter & Parameter level \\
\hline EPANET simulation & $\begin{array}{l}\text { Simulation period of time (duration) } \\
\text { Scenarios (junctions injection set) } \\
\text { Time of injection (moment / duration) } \\
\text { Estimated population } \\
\text { Mass injection rate }\end{array}$ & $\begin{array}{c}\mathbf{4 8} \text { hours } \\
\mathbf{1 2 2} \text { joints } \\
\mathbf{1} \text { hour disinfectant; } \mathbf{1 0} \text { hours contaminant } \\
\mathbf{3 0 6 5 8 5} \text { (basic water requirement) } \\
\mathbf{5 0 ~} \mathrm{mg} / \mathrm{min} \text { disinfectant; } \mathbf{1 7 4 0 0 . 0} \mathrm{mg} / \mathrm{min} \\
\text { contaminant }\end{array}$ \\
\hline $\begin{array}{l}\text { Health Impact Analysis } \\
\text { (HIA) }\end{array}$ & Contaminant (agent) & Registers contaminant data \\
\hline $\begin{array}{c}\text { TSO for the Impact } \\
\text { Analysis }\end{array}$ & $\begin{array}{l}\text { Response time }(\mathrm{min}) \\
\text { Delay }(\mathrm{min}) \\
\text { Detection limit }(\mathrm{mg} / \mathrm{l}) \\
\text { Database filename }\end{array}$ & $\begin{array}{l}\text { By user designation according to accepted impact } \\
\text { values as mg/l for chemicals and toxins or as units/l } \\
\text { for organisms and cells }\end{array}$ \\
\hline $\begin{array}{l}\text { Infrastructure Impact } \\
\text { Analysis (IIA) }\end{array}$ & $\begin{array}{l}\text { Contaminant (agent) name } \\
\text { Concentration thresholds }\end{array}$ & $\begin{array}{l}\text { By user designation as } \mathrm{mg} / \mathrm{l} \text { for chemicals and } \\
\text { toxins or as units/l for organisms and cells }\end{array}$ \\
\hline Sensor Placing (SP) & $\begin{array}{c}\text { Exposing model (water ingestion) } \\
\text { Sensor set sizes (six actual sets) } \\
\text { Response time (three moments) } \\
\text { Detection limits (three values) } \\
\text { Solver algorithm } \\
\text { Objective / Statistics }\end{array}$ & 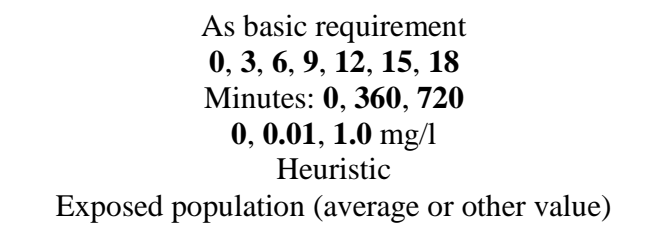 \\
\hline
\end{tabular}

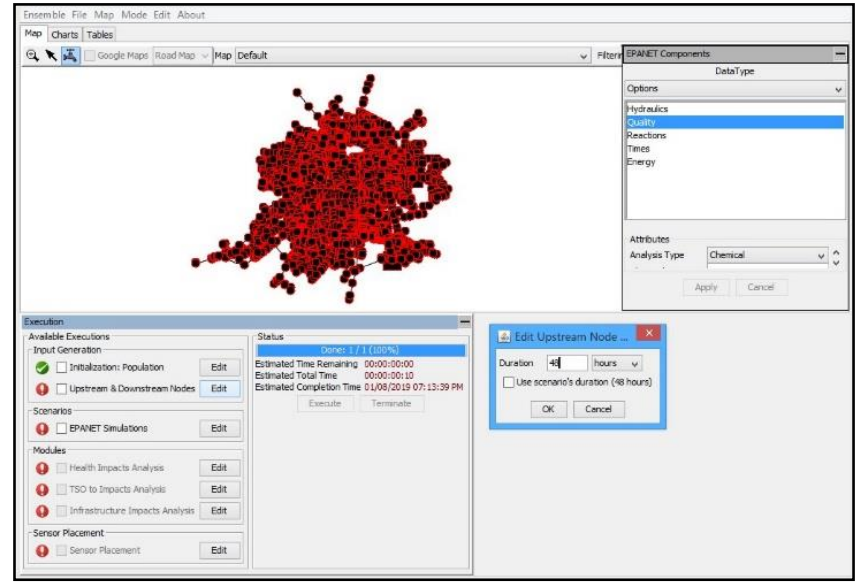

Fig. 5. Upstream \& Downstream Nodes editing and validation under Input Generation in Execution Control sub-menu

Further on, the joints considered to receive the contaminant Agent \#2 are defined - 20713, 14827 and 14108 - here under the node set name "Noduri". The Agent \#2 species is chosen as BIO, its mass injection rate $17400.0 \mathrm{mg} / \mathrm{min}$ starting from hour 3 and stopping at hour 14 , the concentration zero threshold of $0.001 \mathrm{mg} / \mathrm{l}$, the calculated concentration tolerance of 1.0E-6 mg/l. Once data is confirmed, the agent is assigned to the designated joints and all these elements are added to the set scenario. After edit confirmation the EPANET Simulations execution becomes valid, the side box can be checked and the Execute option can be performed. A suitable running was indicated by the approving green dot and so the user was able to move to the next available execution. 
The figure 7 presents the followed procedure for running the Health Impacts Analysis module. First, the Ingestion submenu is stepped through by supplying and validating the specific data. Then the following Inhalation Showering and Inhalation Humidifier sub-menus are either concluded. Once data validation the Execution option was pursued, the suitable processing being indicated by the approving green dot.

Figure 8 shows the accomplishment of Infrastructure Impacts Analysis module where BIO species is specified, and the threshold concentration is supplied. After data confirmation, the module was executed, and the suitable achievement was automatically ratified by the green dot on its left.
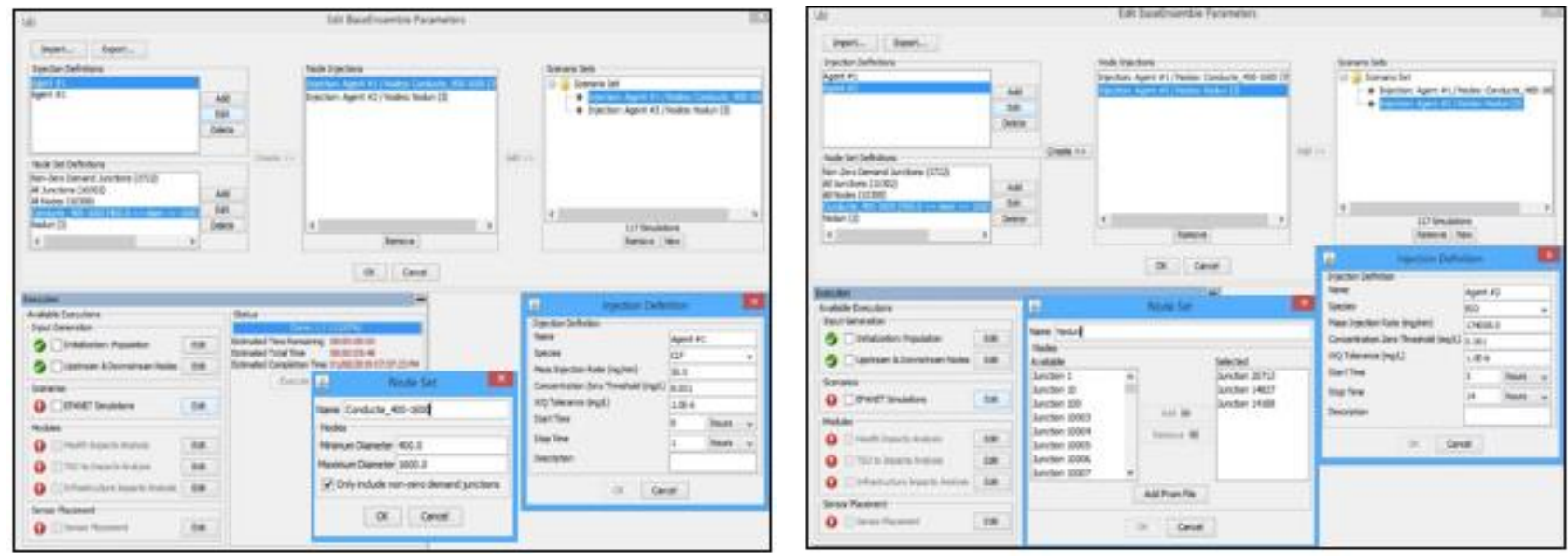

Fig. 6. Performing of Scenarios available execution: upper - contaminant Agent \#1 of CLF species, injected in the nodes associated to defined pipes 400-1600mm; down - contaminant Agent \#2 of BIO species, injected in the 3 designated nodes

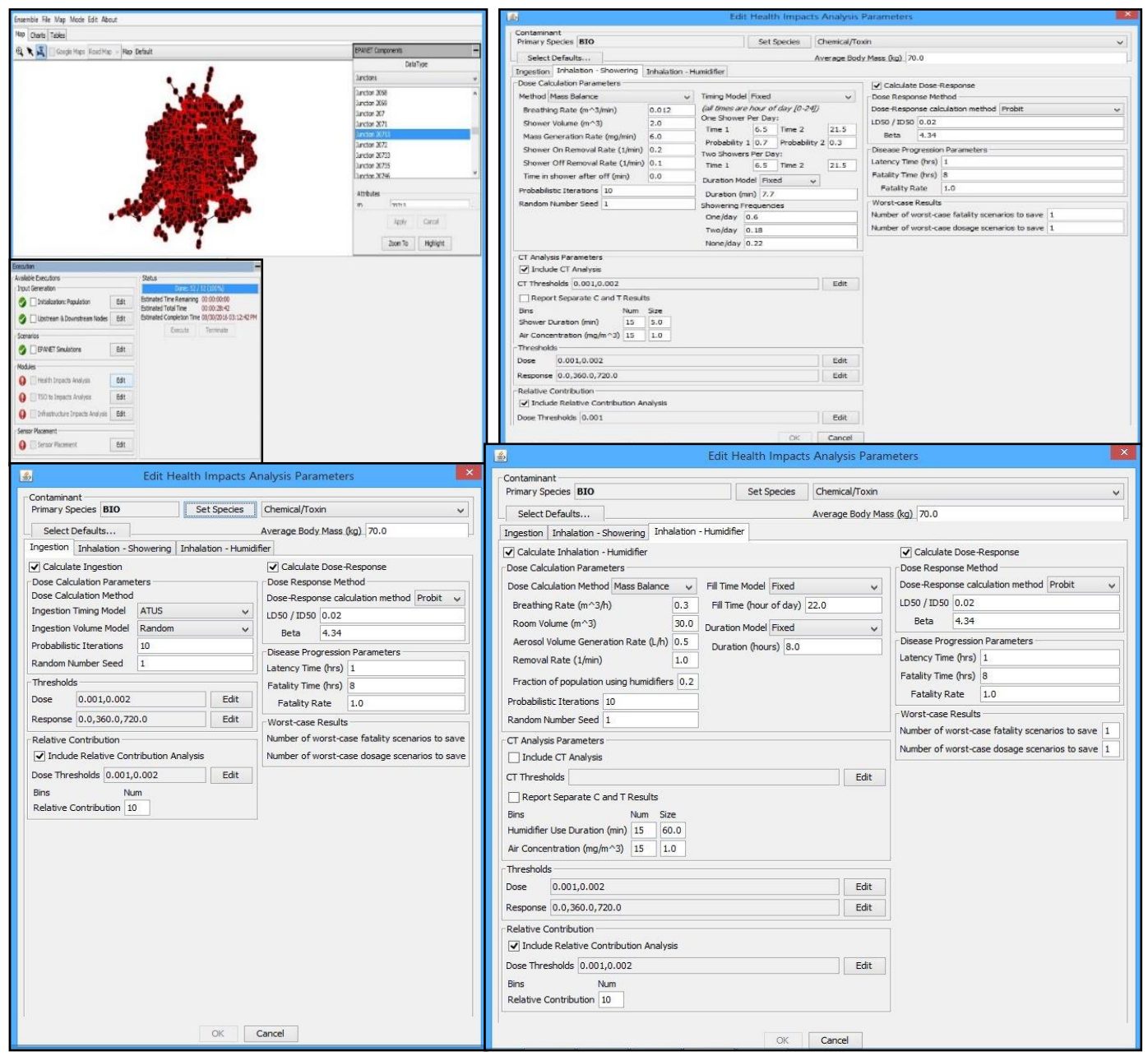

Fig. 7. Performing the Health Impacts Analysis module: specific parameters supplying / assortment for Ingestion, Inhalation-Showering and Inhalation-

Humidifier sub-menus 
The figure 9 presents the edit stage of Sensor Placement execution where sensors set data was considered and validated. The proper execution was ratified by the displayed green dot.

Following the performance of all the described steps in TEVA-SPOT ensemble analysis we were able to reach a series of results that can be sorted as maps, graphs and spreadsheets.

The charts are developed in the ensemble analysis module by running a health impact simulation. No diagram was designate as an embedded graph. By accessing the Charts menu, a rolling list of all graphs produced by performing a HIA will appear. The impact is presented either as a time series or as a cumulative distribution function. Figure 10 shows the time development chart of the $100^{\text {th }}$ percentile case of the estimated infections, diseased and fatalities -1216 total estimated fatalities - when injecting a CLF species agent at a rate of $50 \mathrm{mg} / \mathrm{min}$ along the first hour of simulation period and a BIO species agent at a rate of $17400 \mathrm{mg} / \mathrm{min}$ from the end of the $3 \mathrm{rd}$ hour to the end of the 14th hour.

The output maps are developed both by performing a health impact analysis and by running the sensor placement execution. A rolling list of all the produced maps will open by accessing the Map menu. Conveniently, the map appointment rule follows a specific pattern: the first part refers to considered optimisation solver and the rest of it indicates the sensors number, the optimisation object, the response time, the location categories, the detection limit and finally the selection method. As for this stage, the selection method has no specific significance but is a title for a subsequent approach. Under the given circumstances, the map presented by figure 11 and entitled as SOgrasp-NS018OBpei_mean-RT720-LCConducte-DL1-SMstd refers to detection sensors placement by the following design parameters: grasp (heuristic) solver, number of sensors $=18$, objective $=$ mean estimated population exposed to ingestion, response time $=720 \mathrm{~min}$, location category $=$ pipes, detection limit $=1$ and selection method $=$ standard endowment.

According to the map legend for the Sensor Location option, there are three sensor location categories of different colors assignment: existing, selected or ignored. All the produced sensor drawings will have the following associated maps: sensors locations, detected events at joints, detected events in pipes and detected events both in pipes and at joints.

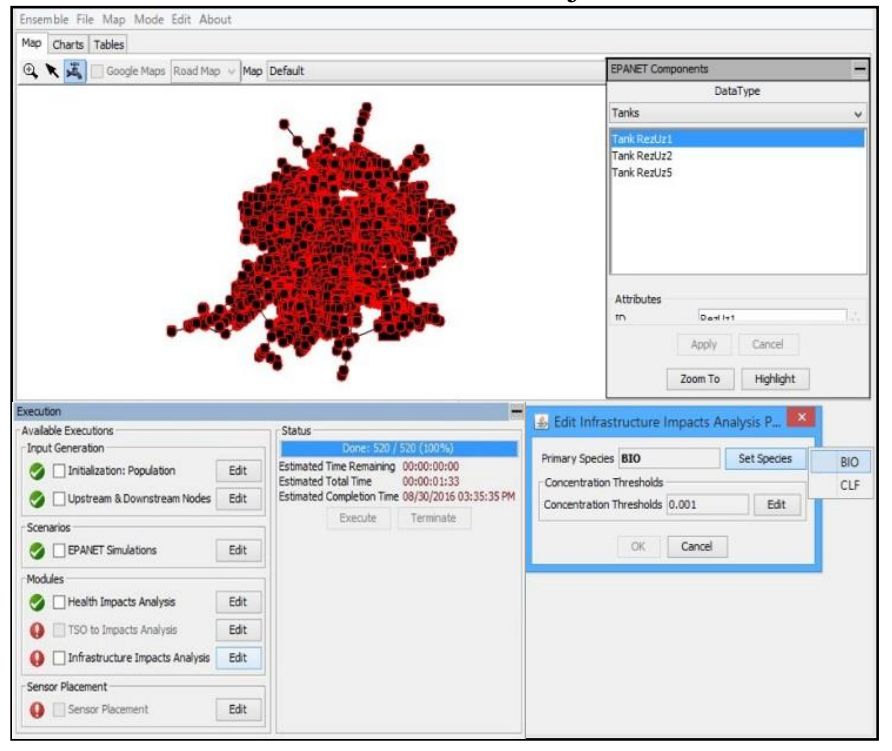

Fig. 8. Execution of Infrastructure Impacts Analysis module

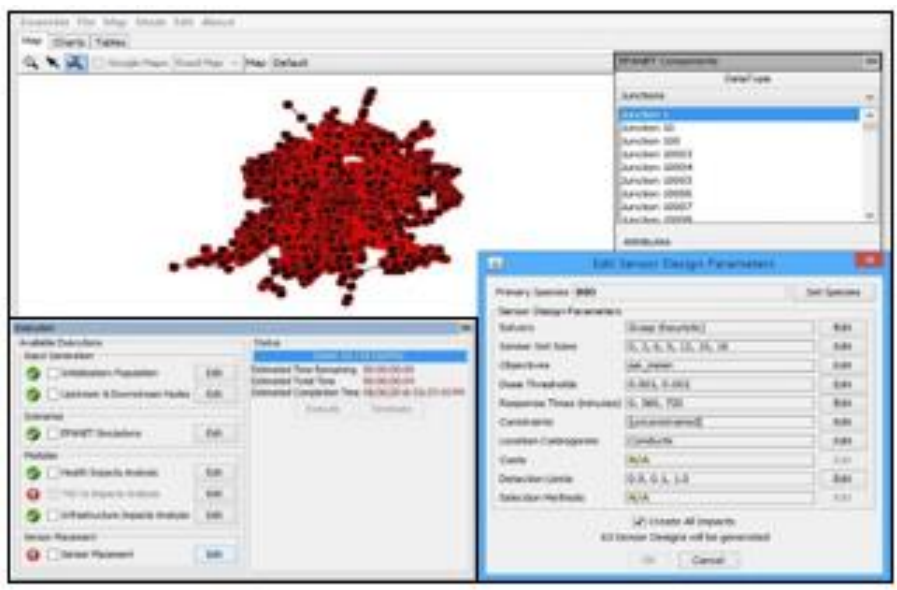

Fig. 9. Approach of Sensor Placement execution 


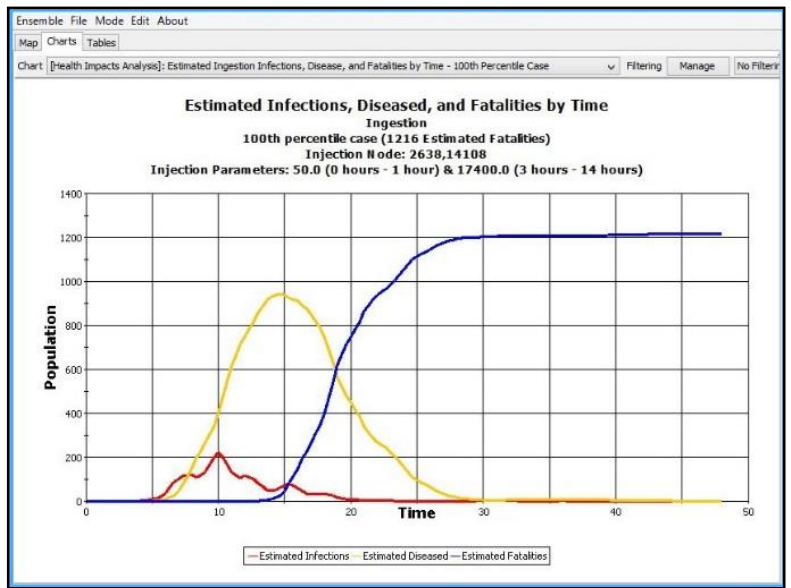

Fig. 10. Time development of the estimated infections, diseased and fatalities

\section{Concluding considerations}

Seven cases with six actual groups of water quality monitoring sensors (numbering $0,3,6,9,12,15,18$ devices) were considered for the numerical model engaging the objective: Mean Estimated Population Exposed - Ingestion. The detection limits in milligrams/liter were set for three levels at $0,0.01$ and 1.0, and the response time was considered as for three moments at minute 0,360 and 720 . The main goal of the performed numerical simulation was to analyze the water distribution system vulnerability at contaminant agents release and the corresponding optimum location of a group of quality monitoring/warning sensors that would help to reduce the effect upon customers.

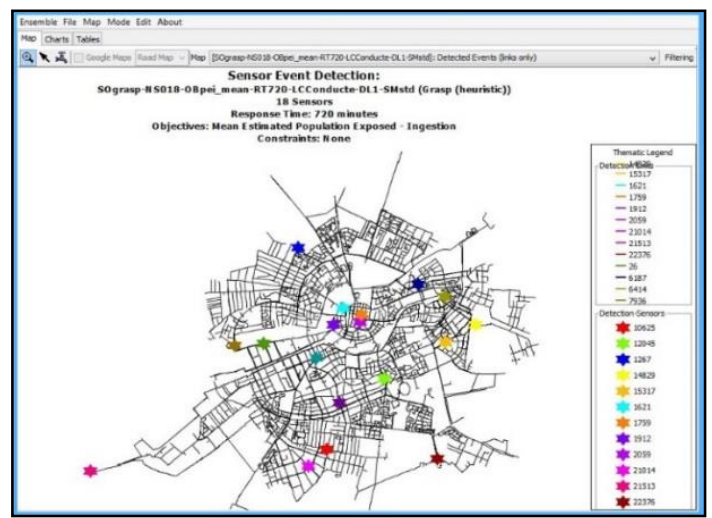

Fig. 11. Optimum locations of the 18 water quality monitoring sensors on the metropolitan network

Since there was no available data regarding the town budget assigned for sensors acquisition, there was not performed any estimation concerning the sensors group size under a given expense. There is also mentioned that an assigned budget should correspondingly cover the cost of a Supervisory Control and Data Acquisition Station database.

Taking into consideration all the given circumstances applied to the drinking water supply network of 11588 pipe segments, there was reached the conclusion that a group of at least 18 sensors should be implemented under the optimum location on the system joints presented by figure 11 .

\section{References}

1.ROSSMAN, L.A., EPANET 2 User's Manual, U.S. Environmental Protection Agency, EPA/600/R-00/057, Cincinnati, OH, 2000.

2. SHANG, F., UBER, J.G., ROSSMAN, L.A., EPANET Multi-Species Extension User's Manual, U.S. Environmental Protection Agency, Washington DC, 2008.

3. ****, Threat Ensemble Vulnerability Assessment - Sensor Placement Optimization Tool (TEVA-SPOT), User's Manual, Version 2.3.0, U.S. Environmental Protection Agency, National Homeland Security Research Center, Washington DC, 2010.

4. ****, Application of TEVA-SPOT for Prioritizing Security Enhancements at Utility Facilities and for Protection of Critical Facilities, U.S. Environmental Protection Agency, EPA/600/R-14/433, Cincinnati, OH, 2014.

5. BERRY, J., HART, W.E., PHILLIPS, C.E., UBER, J.G., WATSON, J.P., Sensor placement in municipal water networks with temporal integer programming models, Journal of Water Resources Planning and Management, Vol. 132 Issue 4, 218-224, July 2006

MIRCHANDANI, P.B., FRANCIS, R.L., Discrete Location Theory, John Wiley \& Sons Publishing House, New York,1990.

CARABET,, A., MIREL, I., FLORESCU, C., STĂNILOIU, C., GÎRBACIU, A.I., OLARU, I., Drinking water quality in water - supply networks, Environmental Engineering and Management Journal, vol. 10(11), pag. 1659-1665, 2011.

MIREL, I., FLORESCU, C., GÎRBACIU, A.I., GÎRBACIU, C.A., DUMITRU, P., DAN, S., Effects of quantitative changes on drinking water quality indicators of urban distribution, Revista Mat. Plast., 52 , no. 4, 2015, p. 125-128

Manuscript received: 20.05 .2019 
